\title{
Gallstone Magnesium Distributions from Optical Emission Spectroscopy
}

\author{
Ashok K. Pathak ${ }^{1}$, Nilesh K. Rai ${ }^{2}$, Rohit Kumar ${ }^{2}$, Pradeep K. Rai ${ }^{3}$, Awadhesh K. Rai ${ }^{4}$ and \\ Christian G. Parigger $5, *$ (D) \\ 1 Department of Physics, Ewing Christian College, Allahabad, Uttar Pradesh 211003, India; \\ akpathak75@gmail.com \\ 2 Department of Physics, Chaudhary Mahadeo Prasad Degree College, Allahabad, \\ Uttar Pradesh 211002, India; nileshkrai162@gmail.com (N.K.R.); rohit.02dec@gmail.com (R.K.) \\ 3 Opal Hospital, DLW Road, Varanasi, Uttar Pradesh 221004, India; pradeepk.rai@gmail.com \\ 4 Department of Physics, University of Allahabad, Allahabad, Uttar Pradesh 211002, India; \\ awadheshkrai@rediffmail.com \\ 5 Physics and Astronomy Department, University of Tennessee, University of Tennessee Space Institute, \\ Center for Laser Applications, 411 B.H. Goethert Parkway, Tullahoma, TN 37388-9700, USA \\ * Correspondence: cparigge@tennessee.edu; Tel.: +1-931-841-5690
}

Received: 17 July 2018; Accepted: 7 August 2018; Published: 9 August 2018

\begin{abstract}
This work reports measurements of calcified gallstone elemental compositions using laser-induced optical emission spectroscopy. The experimental results support the importance of the magnesium concentration in gallstone growth. Granular stones reveal an increased magnesium concentration at the periphery of the granules, suggesting the inhibition of further growth. Non-granular gallstones reveal lower overall magnesium concentrations, but with higher values near the center.
\end{abstract}

Keywords: laser-induced breakdown spectroscopy; atomic spectroscopy; plasma spectroscopy; laser spectroscopy; physical properties of biomaterials

PACS: 42.62.Fi; 52.70.-m; 32.30-r; 52.25.Jm; 87.85.jc

\section{Introduction}

Cholelithiasis affects the morbidity of adults and increases mortality, but it depends on specific population characteristics. For instance, the gallstone disease cases are higher in the north than in the south of India [1]. This work evaluates magnesium concentrations and elemental compositions by collecting spectra during laser ablation of extracted gallstones. Magnesium has many essential roles in fundamental biological functions, and in turn, deficiency provokes several biochemical changes. Sufficient intake is important in maintaining magnesium homeostasis, but the average amount of magnesium in today's menu has diminished over the years. Magnesium is an important mineral constituent of various unprocessed foods such as green leafy vegetables, fish and whole grains. Deficiency of magnesium may cause insulin hyper-secretion and dyslipidemia, which may facilitate gallstone formation [2-6]. Of interest are calcified non-granular, as well as granular gallstones in order to contribute to the understanding of human gallstone progression. However, complimentary in situ diagnoses may further elucidate the role of magnesium in gallstone growth. 


\section{Results}

Figure 1 illustrates typical gallstone appearances and cross-sections. The cross-sectional view of the granular stone (Figure 1b) indicates different granules of different diameters. In this work, it is of particular interest to analyze and quantify granules with different diameters.

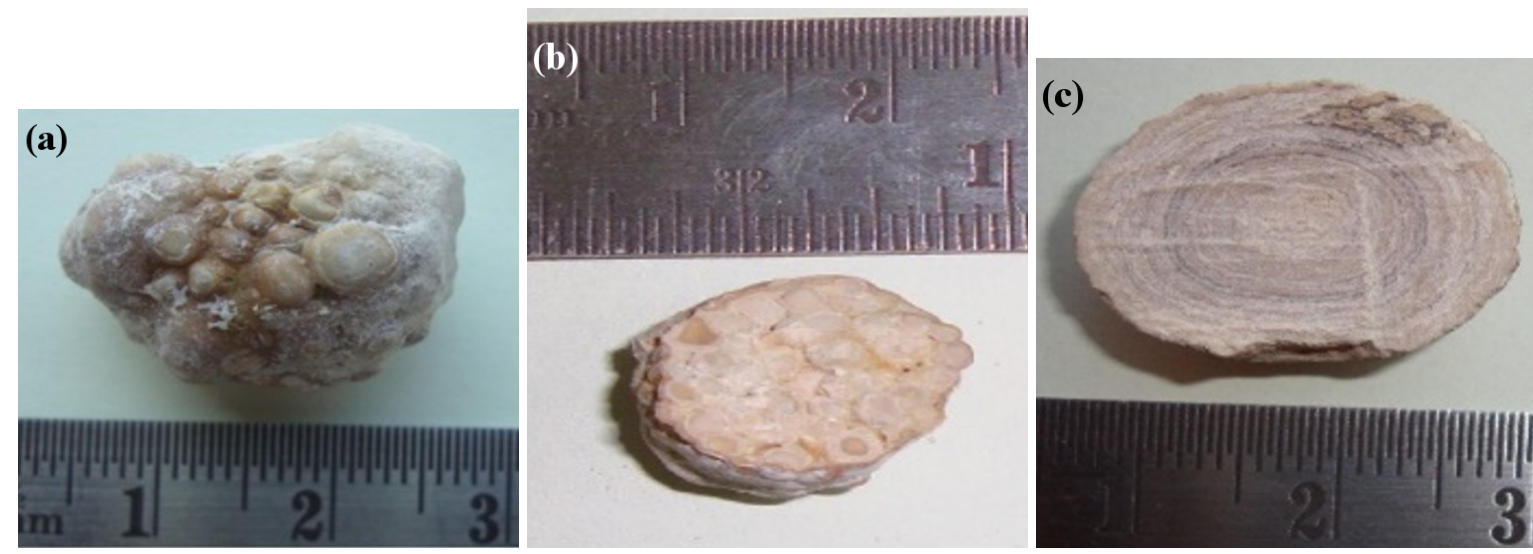

Figure 1. Calcified gallstones: (a) granular gallstone and cross-section of (b) granular and (c) non-granular gallstones.

In the experiments, the samples were mounted on a translation stage and were moved during the measurements. The spectra were collected from different points along the gallstone diameter. The identified spectral lines were due to calcium (Ca), magnesium (Mg), phosphorous (P), iron (Fe), sodium $(\mathrm{Na})$ and potassium $(\mathrm{K})$. The neutral spectral lines of the lighter elements like carbon $(\mathrm{C})$ at $247.8 \mathrm{~nm}$ and $229.6 \mathrm{~nm}$, hydrogen $(\mathrm{H})$ at $656.3 \mathrm{~nm}$ and oxygen $(\mathrm{O})$ at $777.4 \mathrm{~nm}$ have also been identified in the recorded spectra. The simultaneous detection of the lighter elements $\mathrm{C}, \mathrm{H}$ and $\mathrm{O}$ was advantageous in the gallstone experiments. Generating laser-induced breakdown allowed recording and quantifying the occurrence of lighter elements, which in turn confirmed that optical emission spectroscopy was preferred over other conventional analytical techniques such as inductively-coupled plasma-optical emission spectroscopy (ICP-OES).

Figure 2 illustrates typical recorded spectra from granular gallstone in the wavelength range of 200-500 nm. The spectral line positions of the indicated elements have been identified and compared with the National Institute of Standards and Technology (NIST) database [7]. Clearly, the magnesium concentration is higher at the periphery than at the center.

The spectral line intensity was proportional to the concentration of the species. For a particular species transition in the samples, the intensity would directly reflect the concentration if other parameters such as temperature were not to vary significantly. In the experimental runs, the average plasma temperature was within $\pm 10 \%$ as measured using standard Boltzmann plot methods. The recorded spectra of non-granular gallstone (not shown) indicated the presence of the same spectral lines. However, the spectral features showed differences in the intensities of the Mg I 280.2-nm line and the Ca I 393.0-nm line when comparing center and periphery data. Calcified, non-granular gallstones showed concentrations of $\mathrm{Mg}, \mathrm{Ca}, \mathrm{Na}, \mathrm{P}$ and $\mathrm{K}$ that were higher in the center than in the periphery. The relative intensities of the spectral line of $\mathrm{Mg}$ I at $280.2 \mathrm{~nm}$ were recorded by focusing the laser beam at five equidistant points across the gallstone to evaluate the variation of the $\mathrm{Mg}$ concentration. Figure 3 illustrates results for non-granular gallstones in agreement with reported data [8,9], and Figure 3 shows the measured variations for typical 2-mm-3-mm granules investigated in this work. 
(a)

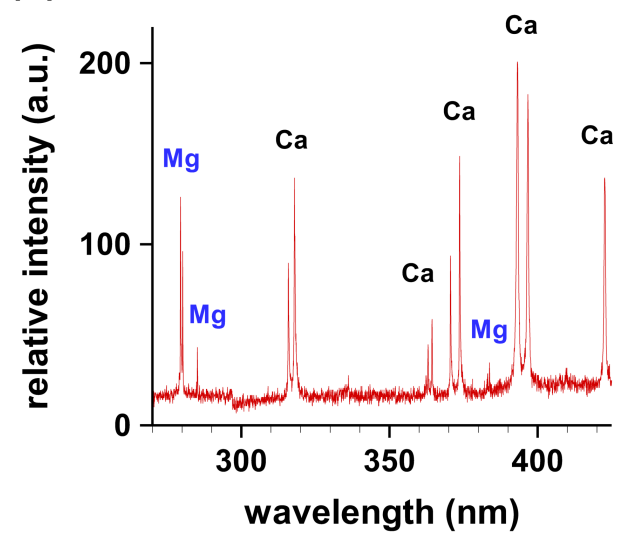

(b)

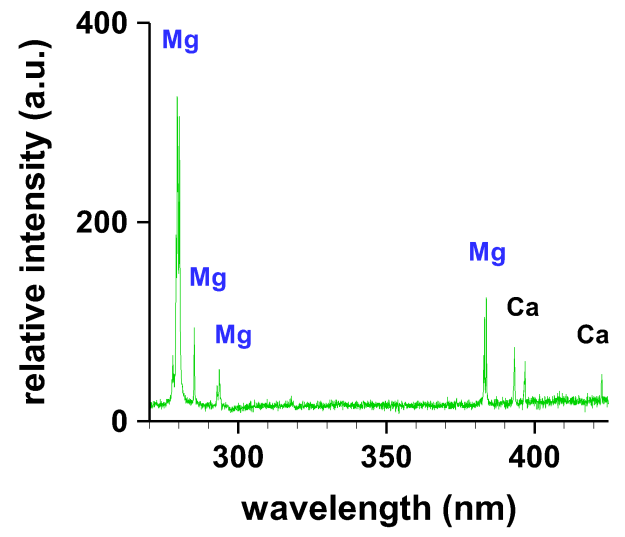

Figure 2. Typical recorded spectral signatures from granules of granular gallstone in the range of 270-450 nm. (a) Center; (b) periphery.

(a)

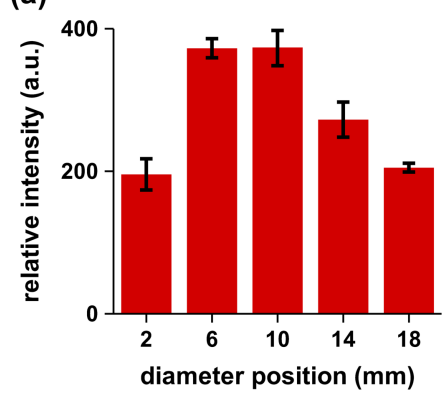

(b)

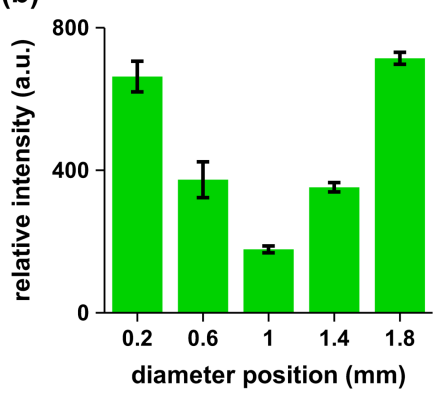

(c)

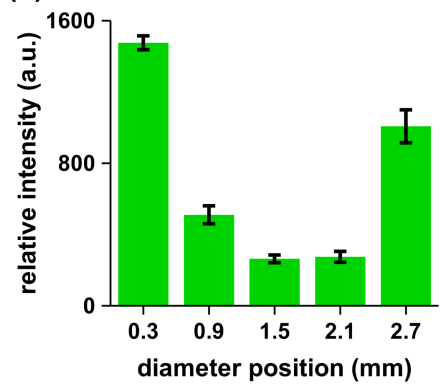

Figure 3. Trends of the measured signals of Mg I $280.2 \mathrm{~nm}$ along cross-sections: (a) 20-mm non-granular gallstone; (b) 2-mm; and (c) 3-mm granules of granular gallstone.

A gallstone continues to grow for $\mathrm{Mg}$ concentrations with a decreasing trend starting from the center or nucleation point. In turn, for $\mathrm{Mg}$ concentrations with an increasing trend starting from the nucleation point, one may infer that gallstone growth is inhibited and causes the formation of small granules. Our experimental observations agree with work reported in the literature [10]. A higher consumption of magnesium is associated with a reduced risk of gallstone disease with a dose-response relationship that is not accounted for by other potential risk factors including other measured dietary variables. The inverse association was also consistently present in the subgroups of potentially confounding variables, which suggest the protective effects of magnesium consumption against cholelithiasis.

\section{Conclusions}

The spatial variations of magnesium concentrations in different granules have been investigated by measuring the $\mathrm{Mg}$ I 280.2-nm line at various points in calcified gallstones. The formation mechanism of granular gallstone appears different from non-granular gallstone samples obtained from the same geographical region. The presented experimental results indicate that $\mathrm{Mg}$ may inhibit or allow further growth of gallstone. Future work is recommended to elaborate and confirm the $\mathrm{Mg}$ dependency on its concentration change from the point of gallstone nucleation. 


\section{Materials and Methods}

The experimental arrangement included a Nd:YAG laser device and a spectrometer equipped with an intensified charge-coupled device. Previous work [11,12] described further details of the experimental setup. Laser pulses of $20 \mathrm{~mJ}$ at a repetition rate were used to record data with acceptable signal-to-background and signal-to-noise ratios. Laser-induced breakdown spectra of the gallstone samples showed a spectral resolution of $0.1 \mathrm{~nm}$ and $0.75 \mathrm{~nm}$ in the spectral range of 200-500 nm and 200-900 nm, respectively. The gallstone samples are from Assam Medical College, Dibrugarh, Assam, in the northeast region of India and were shipped to the laboratory in Allahabad, Uttar Pradesh, in sealed pots for the spectroscopy studies.

Author Contributions: The individual contributions of the authors include: A.K.P., N.K.R., R.K. and A.K.R. conceived of, designed and performed the experiments and drafted the initial version of this paper; P.K.R. contributed medical insight; C.G.P. collaborated on various aspects of this work, edited the initial draft and prepared the manuscript for MDPI submission.

Funding: This research was funded for one of us (AKP) by the University Grants Commission (UGC), New Delhi, India, grant number 8-4(57)/2015(MRP/NRCB).

Acknowledgments: The authors are grateful to Suman Rai and Gauranga D. Baruah for providing the samples along with valuable discussions.

Conflicts of Interest: The authors declare no conflict of interest. The funding sponsors had no role in the design of the study; in the collection, analyses or interpretation of data; in the writing of the manuscript; nor in the decision to publish the results.

\section{References}

1. Mohan, H.; Punia, R.P.S.; Dhawan, S.B.; Ahal, S.; Shekhon, M.S. Morphological spectrum of gallstone disease in 1100 cholecystectomies in North India. Indian J. Surg. 2005, 67, 140-142.

2. Saris, N.E.L.; Mervaala, E.; Karppanen, H.; Khawaja, J.A.; Lewenstam, A. Magnesium: An update on physiological, clinical and analytical aspects. Clin. Chim. Acta 2000, 294, 1-26. [CrossRef]

3. Chakraborti, S.; Chakraborti, T.; Mandal, M.; Mandal, A.; Das, S.; Ghosh, S. Protective role of magnesium in cardiovascular diseases: A review. Mol. Cell Biochem. 2002, 238, 163-179. [CrossRef] [PubMed]

4. He, K.; Liu, K.; Daviglus, M.L.; Morris, S.J.; Loria, C.M.; Horn, L.V.; Jacobs, D.R., Jr.; Savage, P.J. Magnesium intake and incidence of metabolic syndrome among young adults. Circulation 2006, 113, 1675-1682. [CrossRef] [PubMed]

5. Touyz, R.M. Magnesium in clinical medicine. Front Biosci. 2004, 9, 1278-1293. [CrossRef] [PubMed]

6. Fawcett, W.J.; Haxby, E.J.; Male, D.A. Magnesium: Physiology and pharmacology. Br. J. Anaesth. 1999, 83, 302-320. [CrossRef] [PubMed]

7. National Institute of Standards and Technology (NIST) Electronic Database. Available online: http:/ / physics. nist.gov / PhysRefData/ASD/lines_form.html (accessed on 5 March 2018).

8. Singh, V.K.; Singh, V.; Rai, A.K.; Thakur, S.N.; Rai, P.K.; Singh, J.P. Quantitative analysis of gallstones using laser-induced breakdown spectroscopy. Appl. Opt. 2008, 47, G38-G47. [CrossRef] [PubMed]

9. Singh, V.K.; Rai, V.; Rai, A.K. Variational study of the constituents of cholesterol stones by laser-induced breakdown spectroscopy. Lasers Med. Sci. 2009, 24, 27-33. [CrossRef] [PubMed]

10. Tsai, C.J.; Leitzmann, M.F.; Willett, W.C.; Giovannucci, E.L. Long-term effect of Magnesium Consumption on the risk of symptomatic gallstone disease among men. Am. J. Gastroenterol. 2008, 103, 375. [CrossRef] [PubMed]

11. Pathak, A.K.; Singh, V.K.; Rai, N.K.; Rai, A.K.; Rai, P.K.; Rai, P.K.; Rai, S.; Baruah, G.D. Study of different concentric rings inside gallstones with LIBS. Lasers Med. Sci. 2011, 26, 531-537. [CrossRef] [PubMed]

12. Pathak, A.K.; Kumar, R.; Singh, V.K.; Agrawal, R.; Rai, S.; Rai, A.K. Assessment of LIBS for Spectrochemical Analysis: A Review. Appl. Spectrosc. Rev. 2012, 47, 14-40. [CrossRef] 